\title{
Benchmarking technical efficiency of rice farms in Ghana: An empirical application of alternative production frontier approaches
}

\section{Rebecca OWUSU COFFIE}

\author{
The University of Western Australia, Australia, and The University of Cape \\ Coast, Ghana
}

\begin{abstract}
:
Aim: In spite of investments in new technologies to improve upon rice production in Ghana, productivity levels are still low. It is therefore important to assess the efficiency of farmers and identify sources of inefficiency to develop policies to reduce inefficiencies. This paper aims to investigate the extent and drivers of technical efficiency of rice farmers in Ghana.

Design/Research methods: bootstrap data envelopment and restricted single-stage stochastic frontier models are employed to examine the technical efficiency of farmers and its determinants. The data for empirical application come from a farm production survey comprising a total sample of 197 rice farmers in Ghana.

Conclusions and findings: The analyses revealed on average, farmers are about $65 \%$ technically efficient. This result indicates that there is a potential to improve upon technical efficiency of farmers by about 35\% within the existing state of resources and technology. Furthermore, the drivers of technical efficiency were identified as food insecurity status and membership of farmer based organisation. Specifically, the results show an inverse relationship between food insecurity status and technical efficiency; where higher levels of food insecurity are associated with lower levels of technical efficiency. Also, membership of farmer based organisation increases technical efficiency of farmers. Contrary to previous studies, non-farm income and credit access were not identified as significant drivers of technical efficiency among the sampled farmers. On the basis of the findings, policies should aim at reducing food insecurity among farmers and encouraging membership of farmer based organisations.
\end{abstract}

Originality/value of the article: This paper provides evidence-based information on the extent of technical efficiency of rice farmers in Ghana and suggests measures for technical efficiency improvements.

Key words: Technical efficiency, rice production, food insecurity, new technologies, bootstrap data envelopment

JEL: Q1, Q12

Correspondence address: Rebecca Owusu Coffie, 35 Stirling Highway, Perth WA 6009 Australia. E-mail: rebecca.owusu@research.uwa.edu.au

Received: 30.09.2017, Revised: 11.07.2018, Accepted: 11.07.2018

doi: http://dx.doi.org/10.29015/cerem.577 


\section{Introduction}

In Ghana, rice ranks second to maize as an important staple (Coffie et al. 2016; Ragasa et al. 2016) with consumption estimates around $30 \mathrm{~kg} / \mathrm{capita}$ per year and this is predicted to reach $63 \mathrm{~kg} /$ capita per year in 2018. In spite of the increasing demand of the crop, supply does not match up with demand and the deficit in supply is mainly accounted for through imports from other rice producing countries such as Vietnam (Angelucci et al. 2013). Currently, rice import constitutes 58 percent of total cereal imports in the country (Coalition for African Rice Development [CARD] 2010), a trend that is quite problematic because the international rice market is unstable and cannot be relied upon to supply the needed quantity of rice. Ravn (2014) asserted that population pressures and diminishing resources in many rice producing countries may affect the volume of rice traded by 2020, implying that there could be potential increases in prices at the world market, which may affect purchasing power at the domestic market, a phenomenon that would affect food security and general welfare of farmers.

Over the years, many Ghanaian governments have introduced policies with technologies to boost domestic rice production. Notable among these policies are the Medium Term Agricultural Development Programme (MTADP) in 1991-2000, Food and Agriculture Sector Development Policy One (FASDEP I) from 20022003, FASDEP 2 in 2007, Ghana Poverty Reduction Strategy 1 \&2 (GPRS) from 2003-2009 and the Medium Term Agriculture Sector Investment Plan (METASIP) from 2009-2015. These policies have targeted various aspects of improving rice productivity such as the provision of extension services and improved seed varieties, adequate agronomic practices among others. Despite the investments made in the rice industry to boost productivity, production levels are still low. For instance, the average yield of rice per hectare in Ghana (1.9 tonnes/ha) is less than half of that of the world (4.3tonnes/ha). Given the importance of the crop in the country's food security agenda, there are suggestions for improvements in productivity. Performance (technical efficiency) measurement of rice production should, therefore, be considered as a main issue and an adequate policy based on efficiency improvements designed to ensure high production and food security. 
The concept of technical efficiency measurement was initiated by the seminal article of Farrell (1957). In his paper on the measurement of productive efficiency, Farrell (1957) defined a simple measure of a firm's efficiency which accounts for multiple inputs within technical, allocative and economic efficiency. Since its introduction, there has been an expansion of the frontier methodology to investigate efficiency as an econometric and operational research method, with applications in the transport, financial and agricultural industries. Based on Farrell (1957) seminal work, a host of related frontier models classified as parametric and non-parametric were developed. The most common non-parametric frontier model is data envelopment analysis (DEA) proposed by Charnes et al. (1978). On the parametric front, later works led to the development of the stochastic frontier approach to efficiency estimation (Aigner, Chu 1968; Afriat 1972; Richmond 1974).

The revolution of the frontier methodology over time has been an interesting one: the original deterministic parametric frontier analysis has been replaced by DEA, which has increasingly become the most preferred measure of productive efficiency. DEA is mostly preferred because of its numerous advantages. First, it does not require assumptions about the underlying production technology and the error structure. Second, it has the capability to handle multiple inputs and outputs. On the other hand, the main attraction of the stochastic frontier approach (SFA) is its ability to account for noise in the data without necessarily attributing all deviations to inefficiency; the ability to conduct hypothesis testing and confidence interval construction. For extensive review and empirical applications of these two methodologies, see Emrouznejad et al. (2008), Seiford (1994), Bravo-Ureta and Pinheiro (1993), and Coelli (1995). However, in recent times, there have been criticisms of the DEA methodology due to its non-stochastic nature (Simar, Wilson 1998, 2007). Simar and Wilson (2007) highlighted the deficiency of the deterministic DEA method of sample estimates that exaggerate the level of efficiency within a sample. The authors proposed the use of the bootstrap approach to correct the estimates of technical efficiency. The introduction of the bootstrap procedure is meant to introduce stochasticity into the DEA model to account for noise and consequently allowing one to construct confidence intervals. 
Empirically, the application of the frontier methodologies in developing countries has attracted much attention in the literature (Thiam et al. 2001; BravoUreta, Pinheiro 1993; Battese 1992). Thiam et al. (2001) conducted a review of 32 studies on developing countries agriculture. Thiam et al. (2001) study revealed that Asia, in particular, India and Philippines have received the most attention from frontier researchers in developing countries. The study further reviewed an average technical efficiency value of $68 \%$ in developing countries agriculture. Brümmer (2001) also investigated the efficiency of private farms in Slovenia using the two approaches. The study concluded that there is a substantial degree of inefficiency by both methodologies, however, the DEA scores were found to be lower than SFA. In addition, Latruffe et al. (2004) conducted a study into the determinants of technical efficiency of crops and livestock farms in Poland and concluded that the DEA and SFA efficiency estimates are comparable. The study further identified two important determinants of efficiency: education and market integration. A comparative study of the Greek dairy farms was conducted by Theodoridis and Psychoudakis (2008). The results indicated not only the potential of improving the efficiency of the farmers but also the comparable nature of the two approaches of efficiency estimation: SFA and DEA. Although many studies have established the consistency of the results obtained from the two approaches, others have reported conflicting results (Fiorentino et al. 2006; Kumar, Arora 2010).

In the Ghanaian context, the frontier application to agriculture has not received much attention. Only a limited number of studies have examined the technical efficiency of farmers using the parametric frontier methods. For example, Al-Hassan (2008) investigated the technical efficiency of rice farmers in Northern Ghana and found an average technical efficiency of 53\%. The study further found level of education, extension contact, farmers' age, family size as the drivers of technical efficiency. In another study, Al-hassan (2012) evaluated the technical efficiency of farmers in smallholder paddy farms in Ghana and obtained a mean technical efficiency of $64 \%$. The determinants of technical efficiency according to the study were credit availability, family size and non-farm employment. Donkoh et al. (2013) studied the technical efficiency of rice production at the Tono irrigation scheme in the Northern region. Applying the stochastic frontier model to 85 farmers' data, they 
found a mean technical efficiency of $81 \%$. The determinants of efficiency were identified as land, seed, fertilizer, crop expenditure, education and gender. Scope economies and technical efficiency of cocoa agroforestry systems in Ghana was studied by Ofori-Bah and Asafu-Adjaye (2011). The study objective was to examine the extent to which crop diversity affects farmer technical efficiency and whether cost complementarities exist from the sharing of farm inputs on the same plots within cocoa agroforestry industry in Ghana. The study employed the distance function approach of the stochastic frontier model to estimate the set objective. The study found the mean technical efficiency of multiple cropped cocoa farms as $86 \%$. The determinants of technical efficiency by this study were the presence of shade trees, extent of crop diversity, age, education, gender of farmers and full time farming.

The following limitations can be identified from the previous technical efficiency studies in Ghana. Firstly, despite the importance of the bootstrapped DEA model, there have not been any empirical application in the Ghanaian agriculture. Secondly, none of the studies that applied the stochastic frontier model in the Ghanaian agriculture test for theoretical consistency, and impose the restrictions where applicable. Thirdly, previous researchers have not explored the possibility of drawing a comparison between the two approaches to technical efficiency in Ghana. Fourthly, the effects of determinants such as food insecurity and membership of farmer based organisation on technical efficiency have not been fully explored.

In this paper, the aforementioned limitations are addressed by examining the technical efficiency of rice farms in Ghana using restricted stochastic frontier and bootstrap DEA models. The restricted stochastic frontier model is based on the three-step approach introduced by Henningsen and Henning (2009) to impose theoretical restrictions on the stochastic frontier model. The restricted stochastic frontier approach is important to ensure that the estimated production function is theoretically consistent. On the other hand, the bootstrap DEA model follows the formulation of Simar and Wilson (2007). Beyond the estimation of the extent of technical inefficiency in farm production, the single stage stochastic frontier model and the Simar and Wilson (2007) second algorithm are employed to estimate the drivers of technical efficiency, with a specific emphasis on food insecurity and 
membership of farmer based organisation. Food insecurity status of farmers is very important because it tends to affect labour productivity with consequences on farm output. Food insecure farmers are likely to have low farm productivity compared to food secure farmers. Farmer based organisations (FBOs) are vital in delivering services to farmers (Addai et al. 2014). In Ghana for instance, FBOs have become a major policy objective in improving agricultural productivity among small-holder farmers. Specifically, in the area of rural service delivery and farm credit access. It is therefore important to provide evidence on the effects of FBOs on technical efficiency to help in policy formulation for productivity improvements.

The data for the empirical application come from a farm household production survey conducted in Ghana. Fitting restricted stochastic frontier and bootstrap DEA models to the data, an estimated average technical efficiency of 0.65 was obtained, suggesting that there is a potential to increase rice productivity in Ghana within the current state of inputs and technology. The results also showed that rice output is more responsive to intermediate input relative to land and labour inputs. In addition, it was observed that a majority of the sampled farmers are operating under increasing returns to scale, indicating that farm sizes are too small. Furthermore, food insecurity and membership of farmer based organisations were identified as the primary drivers of technical efficiency in Ghana. Therefore, to improve productivity in rice production, government must address the challenges associated with poor food security status of farmers and also encourage membership of farmer based organisations.

The rest of the paper is organised as follows: Section 2 presents production frontier estimation techniques; section 3 discusses model estimation procedure; section 4 describes data used in the empirical application, section 5 presents the empirical results and a comparison of the models, and finally; section 6 , concludes the paper. 


\section{Production frontier estimation techniques}

The frontier represents a best-practice technology among the farms and deviations are referred to as inefficiency. The frontier approach is used to measure productive efficiency. There are two main types of frontier methodology: parametric and non-parametric. The parametric frontiers (stochastic frontier approach-SFA) estimate efficiency using econometric techniques while the non-parametric frontiers (data envelopment analysis-DEA) measure efficiency using linear programming techniques. Also the parametric frontiers are stochastic while the non-parametric frontiers are deterministic. Whiles the deterministic approach assumes that any deviation from the frontier is inefficiency, the stochastic approach accounts for statistical noise. In the present study, both the parametric and non-parametric approaches are employed to examine the technical efficiency of rice farmers in Ghana and to derive its determinants. Following is a detailed specification of the stochastic frontier and the data envelopment models.

\subsection{Stochastic frontier approach}

The stochastic frontier approach (SFA) uses econometric techniques to specify the production, cost, revenue or profit function with a specific shape and makes assumptions about the distribution of the inefficiency and error terms (Eling, Luhnen 2008). The use of this approach may depend on the number of outputs (production function or distance function) and the type of data (cross sectional or panel data). Assuming a single output, the production frontier for $x_{i}$ vector of $K$ inputs may be specified as in (1):

$$
y_{i}=f\left(x_{i}: \beta\right) \cdot T E_{i}
$$

where; $y_{i}$ is the output, $f\left(x_{i}: \beta\right)$ is the production frontier which is deterministic, $\beta$ is the vector of parameters to be estimated and $T E_{\tilde{i}}$ is the output oriented technical efficiency. Reorganising (1) yields technical efficiency: $T E_{i}=\frac{y_{i}}{f\left(x_{i} ; \beta\right)}$. When $T E_{i}=1$, then the DMU is fully efficient, however, if $T E_{i}<1$, then there is a deviation from the frontier. This deviation may entirely be attributed to inefficiency as is the case in deterministic frontiers or noise and inefficiency within the stochastic framework. 
The stochastic frontier model incorporates a composed error structure with a two sided symmetric and a one sided component (Aigner et al. 1977; Van den Broeck et al. 1994). The one sided component reflects inefficiency whiles the two sided one captures the random effects outside the control of the production unit as well as measurement errors and other statistical noise typical of empirical relationships. SFA may be specified as in (2):

$$
y_{i}=f\left(x_{i} ; \beta\right)+v_{i}-u_{i}
$$

where; $v_{i}$ is the stochastic random term (two sided component) indicating effects such as the environmental factors beyond the control of the farmer, measurement errors in the dependent variable and left-out explanatory variables, and $u_{i}$ is the technical inefficiency term representing the factors that can be controlled by the farmer such as farm management factors. The distribution of the inefficiency term can be either half normal $\left(\mathrm{v}_{\mathrm{i}} \sim \operatorname{iin}\left(0, \sigma \mathrm{v}^{2}\right)\right.$, truncated normal $\left(\mathrm{v}_{\mathrm{i}} \sim \mathrm{iiN}^{+}\left(\mu, \sigma \mathrm{v}^{2}\right)\right.$ or exponential ( $v_{i} \sim$ iidexponential) (Stevenson 1990; Aigner et al. 1997; Meeusen, Broeck 1977). SFA further requires a functional form specification, which according to Coelli et al. (2005) is based on the flexibility, linearity, regularity and parsimony of the functional form. Stressing on the flexibility, the normalised translog model provides second order approximation to the underlying technology (Abdulai, Huffman 1998; Coelli et al. 2005). For detailed discussion of the distributional assumptions and their proofs, see Coelli et al. (2005) and Kumbhakar (2003).

The estimation of technical efficiency alone is not enough; we have to identify the sources of inefficiency to derive policies to address those specific factors. In the stochastic frontier literature, the initial approach to accounting for the effects of environmental variables on the production frontier was the two stage approach. The two stage approach involves first stage estimation of the technical efficiency and a second stage regression of the environmental variables on technical efficiency (Battese, Coelli 1995). Over the years, the two stage approach has fallen out of favour in the empirical literature because of the potential biases that it introduces into the model estimations (Battese, Coelli 1995). Battese and Coelli (1995) 
introduced a single-stage estimation technique to address the challenges associated with the two stage approach. The single stage model involves a simultaneous estimation of the production frontier and the drivers of technical efficiency. The environmental variables (hereafter $\mathrm{z}$ variables) when introduced into stochastic frontier model in (2) results in the following specification:

$y_{i}=f\left(x_{i} ; \beta\right)+v_{i}-u_{i}+z_{i}$

where $\mathrm{z}_{\mathrm{i}}$ is a vector of explanatory variables affecting efficiency of the farmers and all other variables are as earlier defined.

\subsection{Data envelopment approach}

The data envelopment approach (DEA) uses linear programming techniques to estimate the efficiency scores, which are measures of performance. The DEA gives a piece-wise linear frontier that envelopes the observed input and output data. The best practice production frontier for a sample of decision making units is constructed through a piecewise linear combination of actual inputs and output. All DMUs that lie on the frontier are referred to as efficient, whiles those that do not lie on the frontier are considered as inefficient. The first DEA model was introduced by Charnes et al. (1978) and ever since, many researchers have recognized it as an excellent tool for performance evaluation. Charnes et al. (1978) DEA model was based on the constant return to scale (CRS) assumption. However, the CRS is only suitable when all farms are operating at the optimal scale. In reality, most farms in developing countries may not be operating on an optimal scale, a situation that requires an alternative approach. Banker et al. (1984) introduced the variable return to scale (VRS) frontier to address the deficiencies of the CRS model.

The DEA model can either be input or output oriented depending on whether an input or output distance function is applied. In most empirical applications, the input oriented model is applied. In this paper, both the input oriented and the output oriented models are employed. The DEA approach assumes that all farms within a sample have access to the same technology for the transformation of a vector of $N$ inputs denoted by $x$, into a vector of $M$, outputs, denoted as $y$. The input set under the variable return to scale is represented by: 


$$
L_{v}(Y)=\left\{\begin{array}{ll}
X: \sum_{j=1}^{n} \lambda_{j} y_{k j} \geq y_{k}, k=1, \ldots s ; \\
\sum_{j=1}^{n} \lambda_{j} x_{i j} \leq x_{k}, \quad i=1, \ldots m ; \\
\sum_{j=1}^{n} \lambda_{j}=1 ; \\
\lambda_{j} \geq 0, & j=1, \ldots n
\end{array}\right\}
$$

The associated variable return to scale, piecewise linear output set and technology are represented as:

$$
P_{v}(x)=\left\{\begin{array}{c}
Y: \sum_{j=1}^{n} \lambda_{j} y_{k j} \geq y_{k}, k=1, \ldots s ; \\
\sum_{j=1}^{n} \lambda_{j} x_{i j} \leq x_{k}, k i=1, \ldots m ; \\
\sum_{j=1}^{n} \lambda_{j}=1 ; \\
\lambda_{j} \geq 0, \quad j=1, \ldots n
\end{array}\right\}
$$

and

$$
T_{v}=\left\{\begin{array}{ll}
(X, Y) ; \sum_{j=1}^{n} \lambda_{j} y_{k j} \geq y_{k}, & k=1, \ldots s ; \\
\sum_{j=1}^{n} \lambda_{j} x_{i j} \leq x_{k}, & i=1, \ldots m ; \\
\sum_{j=1}^{n} \lambda_{j}=1 ; & \\
\lambda_{j} \geq 0, & j=1, \ldots n
\end{array}\right\}
$$

The Farrell (1957) input oriented measure of technical efficiency (defined as minimizing input use in production to produce the same level of output) is obtained by solving the following linear programming problems $N$ times: 
$\mathrm{F}_{\mathrm{v}}\left(\mathrm{Y}_{0}, \mathrm{X}_{0}\right)=\min \theta$

\section{subject to}

$$
\begin{aligned}
& \sum_{j=1}^{n} \lambda_{j} y_{k j} \geq y_{k 0} k=1, \ldots s ; \\
& \sum_{j=1}^{n} \lambda_{j} x_{i j} \leq x_{i 0} \quad i=1, \ldots m ; \\
& \sum_{j=1}^{n} \lambda_{j}=1 ; \\
& \lambda_{j} \geq 0, \quad j=1, \ldots n
\end{aligned}
$$

The output oriented model specified in (8) under the variable return to scale assumption is based on the premise of maximising output from existing resources. These two measures according to Coelli et al. (2005) are equivalent measures of the TE when constant return to scale exist.

$$
\begin{aligned}
& F_{v}\left(Y_{0}, X_{0}\right)=\operatorname{Max} \theta \\
& \text { subject to } \\
& y_{k 0} \leq \sum_{j=1}^{n} \lambda_{j} y_{k j} k=1, \ldots S ; \\
& \sum_{j=1}^{n} \lambda_{j} x_{i j} \leq x_{i 0} \quad i=1, \ldots m ; \\
& \sum_{j=1}^{n} \lambda_{j} x_{i j}=\lambda_{i j} x_{i j} ; \\
& \lambda_{j}=1, \quad j=1, \ldots n \\
& \lambda_{j} \geq 0, \quad j=1, \ldots n
\end{aligned}
$$


where; $\theta$ is the input technical efficiency measure having a value of $0 \leq \theta \leq 1$. If $\theta=1$, then the farmer is efficient. The vector $\lambda$ is an $N \times 1$ vector of weights which defines the linear combination of the peers of the $i$-th farmer. $\mathrm{X} \lambda$ and $\mathrm{Y} \lambda$ are efficient projections on the frontier. $\mathrm{N}^{\prime}$ is an $N \times 1$ vector of ones.

The inability of the standard DEA model to account for measurement errors makes it less desirable for efficiency estimation particularly, in developing countries where data quality is a problem. This is because all deviations from the frontier are attributed to inefficiency. Some attempts have thus been made to introduce statistical properties to the DEA estimator. Simar and Wilson (2007) proposed the bootstrapping procedure to correct for the bias in the DEA estimator. Naïve bootstrapping method has been implemented by some authors (Lothgren 1999; Ferrier, Hirschberg 1997). However, Simar and Wilson (2007) criticise the naïve bootstrapping procedure as yielding inconsistent estimates and suggested that a smoothed bootstrap procedure is a more suitable alternative approach that yields consistent result.

This paper applies the Simar and Wilson (2007) model to correct for bias in the DEA estimator and construct confidence intervals. The central idea behind bootstrapping is to simulate a true sampling distribution by mimicking the data generating process (DGP). The smooth bootstrap procedure is based on the assumption that the distribution of the efficiency scores are normally distributed. Initially, the efficiency scores are estimated from the original data to produce a pseudo data where the output is fixed with an adjustment of the input vector by the estimated efficiency scores. Based on the generated pseudo data, new efficiency scores are calculated for samples in the data. Replicating the process yields the empirical distribution of the efficiency measures. For a detailed description of the bias corrected DEA model, see Simar and Wilson (2007).

\subsubsection{Scale efficiency and return to scale}

Technical efficiency measured by the VRS frontier corresponds to pure technical efficiency, which reflects the managerial performance of farmers to organise inputs into outputs. The pure technical efficiency measure is devoid of scale efficiency, which considers the size of operation. It is therefore important to 
consider the effect of size of operation on farmers' productivity. Scale efficiency (SE) is a measure of the optimal level of production. Specifically, SE is the ratio between the CRS technical efficiency and VRS technical efficiency. The measure of SE provides farmers with the ability to choose the optimum size of resources to attain the expected level of production. Inappropriate size of farm operation (that is either too small or big) may affect technical efficiency of farmers. The type of inefficiency of farm operations resulting in technical inefficiency is referred to as scale inefficiency. Based on scale inefficiency, we can compute the return to scale, which is a relative measure of the relationship between a constant return to scale frontier and a decreasing return to scale frontier. Return to scale can be classed as either increasing return to scale (IRS), decreasing return to scale (DRS) or constant return to scale (CRS). When a farm experiences IRS, then the farm size is too small to be efficient, and under DRS, the farms are too big. Farms operating under CRS indicates the farm has an optimal scale of production.

\section{Data}

The data for the empirical application come from a farm household production survey conducted between August and September 2014 in Northern and Upper East regions of Ghana for the 2013/2014 production season. The two regions were selected as the study sites because of the volume of rice produced and closeness to the major rice market, Ashanti region. A study by Angelucci et al. (2013) revealed that the two regions contribute almost $70 \%$ of the total volume of rice produced and therefore play a major role in the country's food self-sufficiency in rice production. Analysis of technical efficiency of rice production using these two regions is very important to identity regional variations in efficiency for a sound policy recommendation. A multistage sampling technique was employed in the data collection process. In the first stage, the stratified sampling method was used to categorise regions into districts and later communities. The simple random sampling technique was then used to select the farming households based on names provided 
by the Ministry of Food and Agriculture. Using face to face interview techniques, a total of 197 farming households were interviewed.

Based on previous studies, three inputs and a single output were considered in the production function estimation. Output was measured as an amount of paddy rice produced per hectare of rice farm. The inputs include farm size, labour and intermediate inputs. Farm size (X1) was measured as total area cultivated to rice in hectares. Labour (X2), total person-days committed to the production process by both family and hired labour. The family labour who counted are persons of the family unit that reside in the house and are actively involved in the production process, and intermediate input costs (X3): This was an aggregation of other production costs such as harrowing, seed cost, fertilizer cost, ploughing, and herbicides in Ghana Cedis (2.8 Ghana Cedis is equivalent to 1 USD).

With respect to the environmental variables, the following variables were considered: food insecurity, access to credit, membership of farmer based organisations and non-farm income activity. Food insecurity was measured using the Household Food insecurity Access Scale indicator developed by Coates et al. (2007). The raw food insecurity data obtained from the survey contained several variables and could not be used in the estimation directly. A factor analysis was conducted to reduce the number of variables. Specifically, tetrachoic factor analysis was employed to generate food insecurity score. The food insecurity score was used in the final model estimation, a value close to zero is indicative of higher food security and that close to 1 , higher level of food insecurity. The non-farm income variable is a dummy representing whether a farmer is engaged in non-farm income activity or not. Similarly, membership of farmer based organisation measures whether a farmer is a member of farmer based organisation or not. The access to credit variable is also a dummy variable showing whether a farmer has access to credit. 
Table 1. Descriptive statistics of data

\begin{tabular}{|l|c|c|c|c|}
\hline Variable & Mean & SD & Min. & Max. \\
\hline Inputs & & & & \\
\hline Farm size (x1) in ha & 1.21 & 1.013 & 0.405 & 8.098 \\
\hline Labour (x2) in man-days & 121.97 & 318.807 & 5 & 3628 \\
\hline Intermediate input (x3) cost & 499.85 & 371.73 & 50 & 2510 \\
\hline Output & & & & \\
\hline Rice yield (y) & 1761.52 & 1861 & 336 & 21000 \\
\hline & & & & \\
\hline Environmental variables & & & & \\
\hline Food insecurity & 0.24 & 0.48 & 0 & 1 \\
\hline Access to credit ( Yes=1) & 0.157 & 0.365 & 0 & 1 \\
\hline $\begin{array}{l}\text { Farmer group membership } \\
\text { (Yes=1) }\end{array}$ & 0.645 & 0.479 & 0 & 1 \\
\hline $\begin{array}{l}\text { Non-farm income activity } \\
\text { (Yes=1) }\end{array}$ & 0.289 & 0.455 & 0 & \\
\hline
\end{tabular}

Source: Author's own elaboration.

Sample descriptive statistics are presented in Table 1. It is evident from the table that farm sizes are mainly small with an average of about 2 hectares. This is indicative of the small-scale nature of rice production system and typical of production systems in developing countries (Coffie et al. 2016). In addition, it can also be observed from the table that on average, the sample are fairly food secure. The farmer group variable also shows that on average most farmers belong to existing farmer groups. The non-farm income activity variable indicates that most farmers are not engaged in non-farm income activities.

\section{Model estimation}

Five different models were estimated: a single stage restricted translog stochastic frontier model and four variants of the bootstrapped DEA model. Regarding the SFA model, first, a standard model was estimated and then tested for a violation of the monotonicity assumption. The test revealed a violation of the

\footnotetext{
${ }^{1}$ Note that farmer based organisation and farmer group is used interchangeably in this paper.
} 
monotonicity assumption and this was corrected by estimating a restricted model by imposing the assumption. In the frontier literature, three approaches to imposing monotonicity restriction are identified: restricted maximum likelihood estimation (Bokusheva, Hockmann 2006), Bayesian inference approach (O’Donnell, Coelli 2005) and the three-step approach (Henningsen, Henning 2009). The three-step approach was adopted in this paper because it is easy to implement compared to the other approaches (Henningsen, Henning 2009). The three-step approach involves 1) estimating an unrestricted stochastic frontier model and extracting the unrestricted parameters of the frontier and the covariance matrix from the estimation 2) estimating a minimum distance function and extracting the restricted parameters 3 ) determining technical efficiency estimate of the farms and effects of variables explaining inefficiency based on the theoretically consistent frontier. For detailed information about the three-step approach, see Henningsen and Henning (2009). With respect to the bootstrapped DEA model, both the input and output oriented models were estimated under CRS, DRS and VRS using the second algorithm proposed by Simar and Wilson (2007): The approach involves a joint estimation of the frontier and the " $z$ " variables that affect technical efficiency. The estimation of the models was implemented in R statistical programming platform.

\section{Results and discussion}

The results of the estimations are presented as follows. First, the production function estimates for the restricted stochastic frontier analysis model and bootstrapped DEA model estimates are presented. Second, scale efficiency, return to scale and determinants of technical efficiency are discussed.

\subsection{SFA results}

The estimation results from the unrestricted stochastic production function (first step) are presented in Table 2. It is observed from Table 2 that the coefficients of the production inputs are significant and all positive. By production theory, the production function should be monotonic. A test of the monotonicity condition of 
the production frontier showed that apart from the intermediate input, monotonicity is violated at 41.1 percent for the land input and 9.1 percent for the labour input. When monotonicity assumption is violated, the efficiency estimates are not easily interpretable. Given that monotonicity is violated in the data, a restricted model was estimated following the minimum distance approach of Henningsen and Henning (2009). Tables 3 and 4 report the estimates from the restricted model estimation. The last column in Table 3 shows the estimates from the restricted coefficients after adjusting the production frontier with the estimates in the final step. Results of the minimum distance function presented in Table 3 show that many of the coefficients have changed, however, similar to the unrestricted function (Table 2), production is more responsive to intermediate inputs. The estimated model parameters are considered as theoretically consistent.

\section{Table 2. Unrestricted stochastic frontier estimation}

\begin{tabular}{|c|c|c|}
\hline Parameters & Estimate & Std. error \\
\hline \multicolumn{3}{|c|}{ Production function } \\
\hline$\beta_{0}$ & $0.416^{* * * *}$ & 0.064 \\
\hline$\beta_{1}$ & $0.191 * *$ & 0.059 \\
\hline $\bar{\beta}_{2}$ & $0.273 * * *$ & 0.037 \\
\hline$\beta_{3}$ & $0.593 * * *$ & 0.055 \\
\hline$\beta_{11}$ & $0.217^{*}$ & 0.108 \\
\hline$\beta_{12}$ & $0.132 *$ & 0.054 \\
\hline$\beta_{13}$ & -0.077 & 0.075 \\
\hline$\beta_{222}$ & 0.075 . & 0.041 \\
\hline$\beta_{23}$ & 0.131. & 0.069 \\
\hline$\beta_{33}$ & 0.082 & 0.103 \\
\hline$\sigma^{2}$ & $0.385^{* * * *}$ & 0.075 \\
\hline$Y$ & $0.891 * * *$ & 0.047 \\
\hline \multicolumn{3}{|c|}{ Inefficiency effects function } \\
\hline$\delta_{1}$ & -0.257 & 0.187 \\
\hline$\delta_{2}$ & -0.481 & 0.337 \\
\hline $\mathrm{S}_{3}$ & $0.271 * * *$ & 0.040 \\
\hline$\delta_{4}$ & $-0.447 *$ & 0.176 \\
\hline
\end{tabular}

Source: Author's own elaboration.

NB: $\delta_{1}=$ Non-farm income, $\delta_{2}=$ credit access, $\delta_{3}=$ food insecurity, $\delta_{4}=$ farmer organisation membership

Considering the adjusted input elasticities (last column, Table 3), it is observed that output is more responsive to intermediate input, followed by labour input and land input. The input elasticity of intermediate input (0.575) implies that a unit 
change in intermediate input will result in 0.575 change in output. Similarly, a percentage change in labour and land inputs will cause a 0.294 and 0.136 change in output, respectively. Regarding return to scale, which is a summation of the first order input elasticities (1.005), we observe that farmers are operating under a slightly increasing return to scale. The cross-product of the input elasticities are relatively small, giving indication of a limited opportunity for input substitution.

Table 3. Minimum distance estimation

\begin{tabular}{|l|c|c|c|}
\hline Parameters & Estimate & Diff. & Adj. estimates \\
\hline$\beta_{0}^{0}$ & 0.485 & 0.069 & 0.484 \\
\hline$\beta_{1}^{1}$ & 0.136 & -0.055 & 0.136 \\
\hline$\beta_{2}^{2}$ & 0.295 & 0.022 & 0.294 \\
\hline$\beta_{3}^{a}$ & 0.576 & -0.017 & 0.575 \\
\hline$\beta_{11}^{0}$ & 0.041 & -0.176 & 0.041 \\
\hline$\beta_{12}^{0}$ & 0.032 & -0.1 & 0.031 \\
\hline$\beta_{12}^{0}$ & -0.044 & 0.033 & -0.044 \\
\hline$\beta_{22}^{0}$ & 0.082 & 0.007 & 0.082 \\
\hline$\beta_{23}^{0}$ & 0.088 & -0.043 & 0.088 \\
\hline$\beta_{33}^{0}$ & 0.070 & -0.012 & 0.070 \\
\hline
\end{tabular}

Source: Author's own elaboration.

The final model estimates in Table 4 show that the coefficient of the intercept is almost zero and the coefficient of the "frontier output" is closer to one, implying that the coefficients of the adjusted and the non-adjusted restricted production frontier estimates (Table 3) are almost identical. This result is comparable with the findings of Henningsen and Henning (2009). Unlike the findings of Henningsen and Henning (2009), there is a slight variation in the total error variance between the unrestricted (Table 2) and final model estimates (Table 4) after imposing the monotonicity restriction. Also, there is a decrease in the proportion of the variance of technical efficiency in the total error variance after imposing the restriction. 


\subsubsection{Partial production elasticity}

The response of output to varying levels of each of the production inputs while holding the levels of the other inputs constant was examined. Results of the input elasticity calculated from the partial frontiers presented in Table 5 show that the elasticity values of all the inputs are positive, implying that output can be increased by increasing the level of individual inputs. The mean partial production elasticity of land increased from 0.077 in the unrestricted model to 0.117 in the restricted model. Similarly, the mean partial elasticity of the labour input increased from 0.171 to 0.223 after imposing the monotonicity restriction. Finally, the mean partial elasticity of the intermediate input increased slightly from 0.522 to 0.524 in the restricted model. A mean comparison test was calculated to test whether there is significant difference between the restricted and unrestricted parameters. The results show that there is a significant difference between the restricted and unrestricted estimates except for the intermediate inputs.

Table 4. Final stochastic frontier estimation

\begin{tabular}{|l|c|c|}
\hline Parameters & Estimate & Std. error \\
\hline$a_{0}$ & 0.005 & 0.046 \\
\hline$a_{1}$ & $0.997^{* * *}$ & 0.055 \\
\hline$\sigma^{2}$ & $0.382^{* * *}$ & 0.071 \\
\hline$Y$ & $0.879^{* * *}$ & 0.043 \\
\hline $\mathbb{S}_{1}$ & -0.241 & 0.191 \\
\hline $\mathcal{E}_{2}$ & -0.26 & 0.279 \\
\hline $\mathbb{S}_{a}$ & $0.268^{* * *}$ & 0.041 \\
\hline $\mathbb{S}_{4}$ & $-0.449^{*}$ & 0.180 \\
\hline
\end{tabular}

Source: Author's own elaboration.

NB: $\delta_{1}=$ Non-farm income, $\delta_{2}=$ credit access, $\delta_{2}=$ food insecurity, $\delta_{4}=$ farmer organisation membership

Table 5. Partial production elasticity

\begin{tabular}{|l|l|l|l|l|l|l|}
\hline & \multicolumn{3}{|c|}{ Unrestricted model } & \multicolumn{3}{c|}{ Restricted model } \\
\hline & $\mathrm{X} 1$ & $\mathrm{X} 2$ & $\mathrm{X} 3$ & $\mathrm{X} 1$ & $\mathrm{X} 2$ & $\mathrm{X} 3$ \\
\hline Mean & 0.077 & 0.171 & 0.522 & 0.117 & 0.223 & 0.524 \\
\hline Std. & 0.189 & 0.163 & 0.138 & 0.042 & 0.108 & 0.098 \\
\hline Min & -0.437 & -0.117 & 0.174 & 0.000 & 0.000 & 0.292 \\
\hline max & 0.72 & 0.734 & 1.064 & 0.249 & 0.664 & 0.898 \\
\hline
\end{tabular}

Source: Author's own elaboration. 
Next, a graphical correlation plot (Figures 1-3) is constructed to illustrate effects of imposing monotonicity restriction on the production input elasticities. The figures reveal that estimates based on the restricted and the unrestricted models are highly correlated with coefficient correlation of $0.91,0.92$ and 0.99 for land, labour and intermediate inputs, respectively. Although there is nearly perfect correlation between the restricted and the unrestricted input coefficients, one cannot conclude that models that do not impose theoretical restrictions on the production frontier are accurate. This is mainly because theoretically inconsistent production frontier would likely affect further estimations from the production frontier (O'Donnell, Coelli 2005).

Figure 1. Partial production elasticities of land input. Note the unfilled circles show observations with monotonicity violated in the unrestricted model

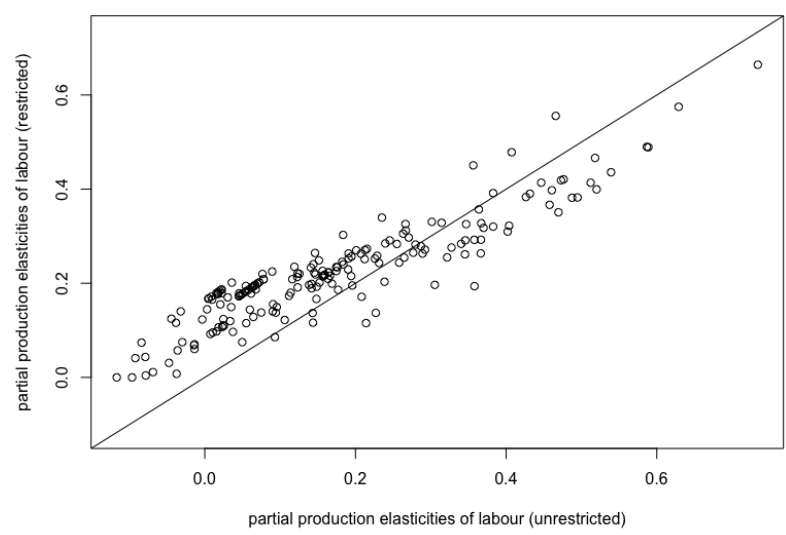

Source: Author's own elaboration. 
Figure 2. Partial production elasticities of labour input. Note the unfilled circles show observations with monotonicity violated in the unrestricted model

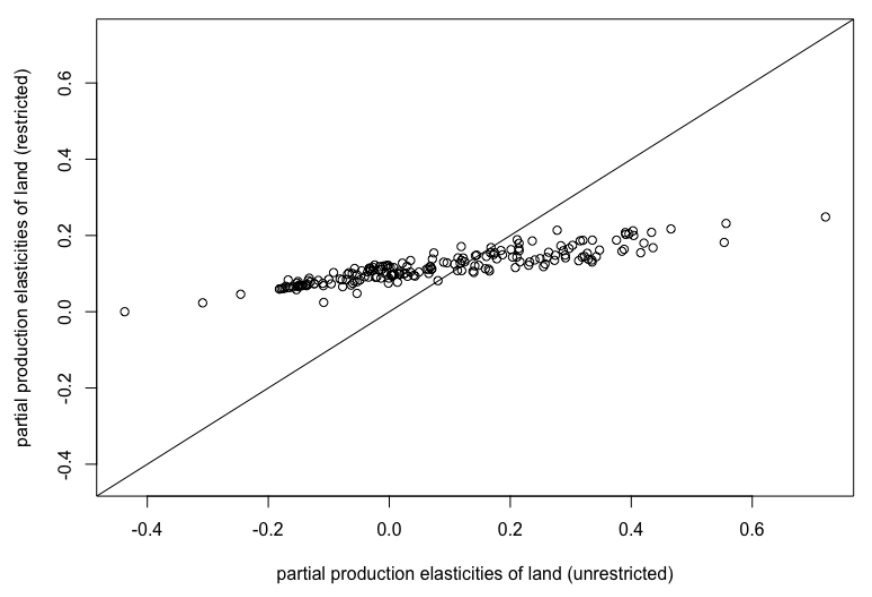

Source: Author's own elaboration.

Figure 3. Partial production elasticities of intermediate input. Note the unfilled circles show observations with monotonicity violated in the unrestricted model

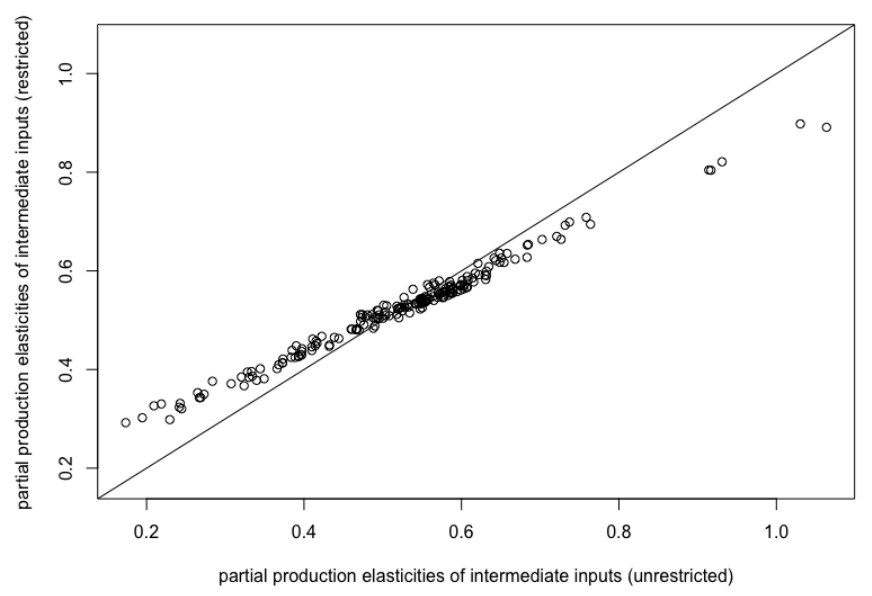

Source: Author's own elaboration. 


\subsection{DEA results}

The input and output oriented DEA technical efficiency model estimates under variable return to scale (VRS), constant return to scale (CRS) and decreasing return to scale (DRS) are presented in Table 6. Columns 2-5 represent the input oriented model estimates, whiles the output oriented model estimates are presented in columns 6-10. The average technical efficiency under the VRS frontier for the standard DEA model for the input and output oriented specifications are 0.72 (Table 2 ) and 0.57 , respectively. Correspondingly, the bias corrected estimates are 0.650 and 0.49 for the input and output oriented models, respectively. Based on the technical efficiency estimates, there is a potential to increase rice yield in Ghana with the available input and technology. The estimates obtained under the CRS and DRS models within the input oriented and output oriented models are similar and much lower than the VRS frontier estimates. These findings confirm previous studies outcome that the VRS frontier results in higher technical efficiency estimate (Matawie, Assaf 2010). The result further implies the standard DEA model has an upward bias (Balcombe et al. 2008).

Next, interval estimates of technical efficiency are discussed. As can be observed from the table, the average point estimates of technical efficiency have 0.1 , 0.2 interval for the $95 \%$ confidence interval for the output and input oriented models under the CRS, VRS and DRS, respectively. However, the more efficient farms within the sample, the $95 \%$ confidence interval is significantly wider as can be illustrated by the minimum and maximum results for alternative orientations for the input and output oriented models, respectively. 
Table 6. DEA input oriented technical efficiency estimates and determinants of technical efficiency

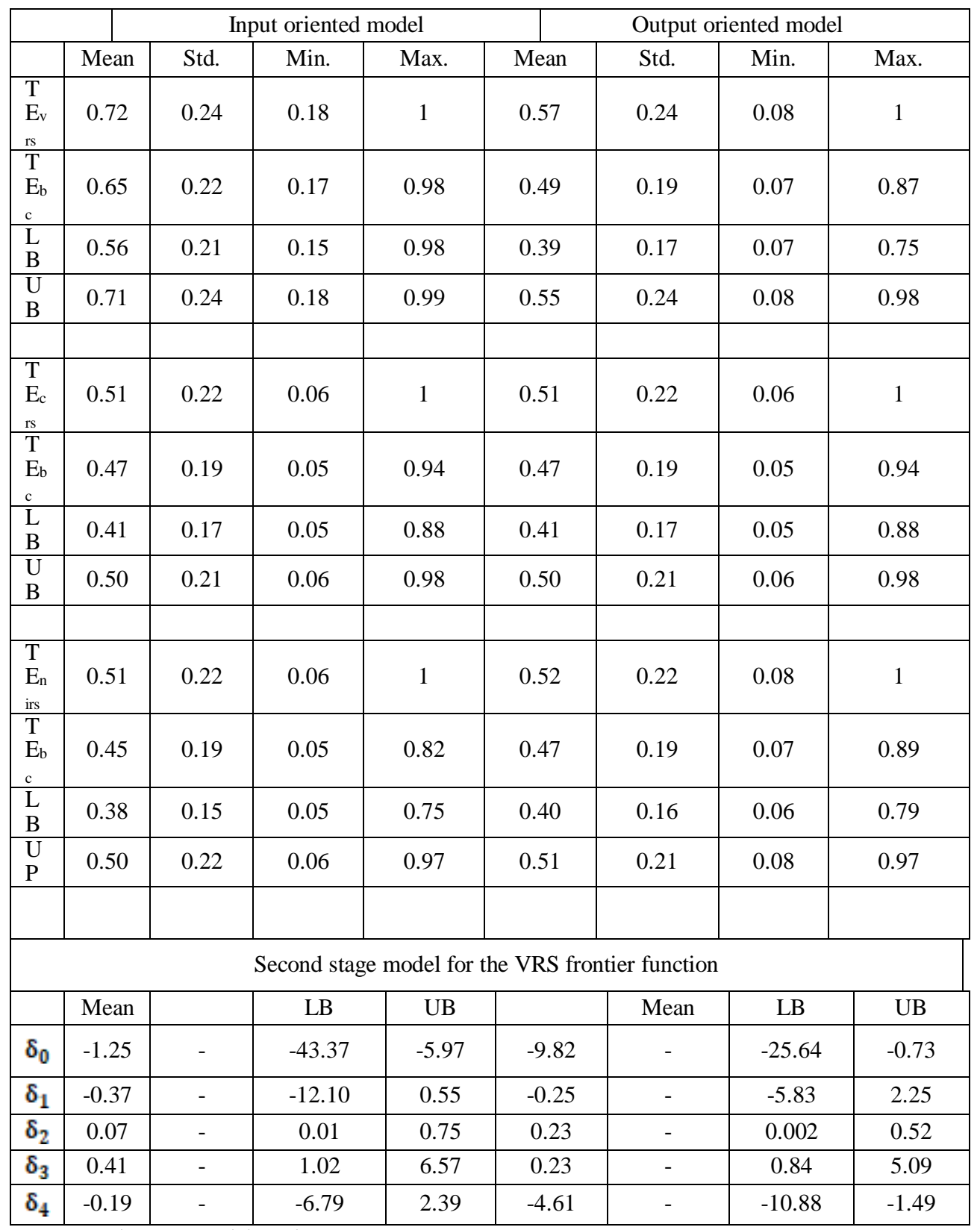

Source: Author's own elaboration.

NB: LB-Lower bound, UB-Upper bound, $\delta \_1=$ Non-farm income, $\delta \_2=$ credit access, $\delta \_3=$ food insecurity, $\delta_{-} 4=$ farmer organisation membership 


\subsubsection{Scale efficiency and nature of return to scale}

Inefficiency in farm production may be attributable to either pure technical inefficiency or scale inefficiency. The subject of scale inefficiency is briefly discussed here. Scale efficiency and nature of return to scale were calculated from the DEA frontiers. Specifically, scale efficiency was calculated as the ratio of the CRS technical efficiency to the VRS technical efficiency, whiles the nature of return to scale was examined as the ratio of CRS to DRS technical efficiencies. The calculated mean scale efficiency and the nature of return to scale are presented in Table 7. From the table, the calculated scale efficiency value of $74 \%$ suggests that scale inefficient farms can reduce size by $26 \%$ without affecting the current output levels. With respect to nature of return to scale (Table 7), the result show that about two thirds of the sample farms operate under increasing return to scale, implying that these farms are too small to be efficient. They therefore have to expand operations to produce on the production frontier. Another 24 farms operate under constant return to scale and these farms are fully scale efficient. Finally, 14 farms operate under decreasing return to scale, suggesting that these farms are not fully technically efficient because they are too large.

Table 6. Scale and nature of return to scale estimates

\begin{tabular}{|l|c|c|}
\hline Nature of return to scale & Number of farms & Percent \\
\hline IRS & 157 & 79.7 \\
\hline DRS & 14 & 7.1 \\
\hline CRS & 27 & 13.7 \\
\hline & & \\
\hline Scale efficiency & & Percent \\
\hline Mean & - & 74 \\
\hline Std. & - & 24 \\
\hline Min & - & 21 \\
\hline Max. & - & 100 \\
\hline
\end{tabular}

Source: Author's own elaboration.

Note: IRS-increasing return to scale, DRS-decreasing return to scale, CRS-constant return to scale

\subsection{Drivers of technical efficiency}

The drivers of technical efficiency are now examined. The second block of Table 3 reports on the inefficiency effects model from the stochastic frontier approach, whiles that of the DEA model is reported in the second block in Table 6. 
The simultaneous estimation approach was adopted in the SFA model estimation, whiles the second algorithm of Simar and Wilson (2007) bootstrap DEA function was employed in the DEA model. Following previous studies (Simar, Wilson 2007; Balcombe et al. 2008), a positive sign on an explanatory variable indicates an obstacle to technical efficiency, while a negative sign indicates a positive influence on technical efficiency. From the tables, it is observed that the food insecurity variable is negative and significant, suggesting that lower levels of food insecurity increases the technical efficiency of farmers. Also, the farmer group membership is negative and significant, indicating that farmer group membership increases technical efficiency of farmers. This finding is similar to previous studies (Bhatt, Bhatt 2014) outcome of the effects of farmer group membership on technical efficiency. Unlike previous studies (Villano, Fleming 2006), the non-farm income variable was not significant in explaining technical efficiency of farmers. The access to credit variable is also not a significant driver of technical efficiency in the sample.

\subsection{Model comparison}

A comparison is drawn between the restricted and unrestricted SFA estimates and also between the SFA and DEA model estimates. First, estimates from the two functions are similar, a finding that corroborates Henningsen and Henning (2009) study outcome. This is confirmed by the near perfect correlation of the technical efficiency estimates in Figures 4-5. Comparing the technical efficiency of the DEA model (output oriented) and that of the SFA model, it is observed that the DEA model technical efficiency estimate is slightly lower than the SFA model estimates, however, the technical efficiency estimates from the two models are highly correlated. Similar findings have been reported in Balcombe (2008) study on alternative frontier methodologies in Austrian dairy farms. The positive correlation between the SFA and the DEA model estimates show that either methodology could be employed in estimating the technical efficiency of farmers in developing countries, particularly when one accounts for biases in the DEA model. 


\section{Conclusions}

The demand for rice in Ghana does not commensurate domestic supply. Over the years, various Ghanaian governments have introduced policies with new technologies to promote rice productivity in Ghana. With an increasing investment in rice production, it is becoming important for farmers to become more efficient in their ability to access and use available technologies to improve productivity. Improving productivity requires adequate assessment of farmers' efficiency and identification of the sources of inefficiency so that better policy and institutional innovations could be introduced to reduce inefficiencies in rice production. In this paper, the restricted single stage stochastic frontier (SFA) and the bootstrap data envelopment (DEA) models are applied to examine the technical efficiency of rice farms in Ghana.

Employing a total sample of 197 rice farms, the mean technical efficiency estimates were 0.65 for the SFA and 0.49 for the input oriented DEA model, suggesting that DEA potentially underestimates the technical efficiency of farmers. Based on the SFA estimate, it can be inferred that farmers can increase rice output by $35 \%$ within the existing state of inputs and technology. In addition, the results revealed that rice output is more responsive to intermediate input use. Generally, however, production is inelastic with respect to the inputs used in the production process. Furthermore, the results indicate that there is less avenue for input substitution. The mean scale efficiency was $74 \%$ with majority of the farmers exhibiting increasing return to scale, suggesting that generally, farmers have the capability to increase output with the current resources available to them.

Regarding the drivers of technical efficiency, food insecurity and membership of farmer based organisation were identified as the primary drivers of technical efficiency among the sampled farmers. Policy makers should therefore initiate measures to improve the food security status of farmers and encourage them to become members of farmer based organisations. 


\section{BENCHMARKING TECHNICAL EFFICIENCY OF RICE FARMS IN GHANA...}

\section{References}

Abdulai A., Huffman W.E. (1998), An examination of profit inefficiency of rice farmers in Northern Ghana, „Economic Staff Paper Series”, Iowa State University, https://lib.dr.iastate.edu/cgi/viewcontent.cgi?article=1295\&context=econ_las_staffpapers [09.09.2018].

Addai K.N., Owusu V., Danso-Abbeam G. (2014), Effecrts of farmer based organisation on the technical efficiency of maize farmers across various agro-ecological zones of Ghana. „Journal of Economics and Development Studies", vol. 2 no. 1, pp. 141-161.

Afriat S.N. (1972), Efficiency estimation of production functions, „International Economic Review”, vol. 13 no. 3, pp. 568-598.

Aigner D.J., Chu S.-F. (1968), On estimating the industry production function, „The American Economic Review”, vol. 58 no. 4, pp. 826-839.

Aigner D., Lovell C., Schmidt P. (1977), Formulation and estimation of stochastic frontier production function models. „Journal of Econometrics”, vol. 6 no. 1, pp. 21-37.

Al-Hassan S. (2008), Technical efficiency of rice farmers in Northern Ghana, Research paper, African Economic Research Consortium.

AL-Hassan S. (2012), Technical efficiency in smallholder paddy farms in Ghana. An analysis based on different farming systems and gender, ,Journal of Economics and Sustainable Development”, vol. 3 no. 5, pp. 91-105.

Angelucci F., Asante-Poku A., Anaadumba P. (2013), Analysis of incentives and disincentives for rice in Ghana, „Monitoring African Food and Agricultural Policies”, FAO, Rome.

Balcombe K., Fraser I., Latruffe L. et al. (2008), An application of the DEA double bootstrap to examine sources of efficiency in Bangladesh rice farming, „Applied Economics”, vol. 40 no. 15, pp. 1919-1925.

Battese G.E. (1992), Frontier production functions and technical efficiency. A survey of empirical applications in agricultural economics, ,Agricultural Economics”, vol. 7 no. 3-4, pp. 185-208.

Battese G.E., Coelli T.J. (1995), A model for technical inefficiency effects in a stochastic frontier production function for panel data, „Empirical Economics”, vol. 20 no. 2, pp. 325-332.

Bokusheva RA., Hockman H. (2006), Production risk and technical inefficiency in Russian agriculture, „European Review of Agricultural Economics”, vol. 33, no. 1, pp. 93-118.

Bravo-Ureta B.E., Pinheiro A.E. (1993), Efficiency analysis of developing country agriculture. A review of the frontier function literature, „Northeastern Agricultural and Resource Economics Association", vol. 0 no. 1, pp. 1-14.

Brümmer B. (2001), Estimating confidence intervals for technical efficiency. The case of private farms in Slovenia, „European Review of Agricultural Economics”, vol. 28 no. 3, pp. 285-306.

Coalition for African Rice Development (CARD) (2010), Mapping of poverty reduction strategy papers (PRSPs), sector strategies and policies related to rice development in Ghana, 
https://riceforafrica.net/downloads/CARD\%20DOCS/Ghana_Mapping_report_Final_version.pdf [09.09.2018].

Charnes A., Cooper W.W., Rhodes E. (1978), Measuring the efficiency of decision making units, „European Journal of Operational Research”, vol. 2 no. 6, pp. 429-444.

Coelli T.J. (1995), Recent developments in frontier modelling and efficiency measurement, „Australian Journal of Agricultural and Resource Economics”, vol. 39 no. 3, pp. 219-245.

Coelli T.J., Rao D.P., O’Donnell C.J., Battese G.E. (2005), An introduction to efficiency and productivity analysis, Kluwer Academic Publishers, Boston.

Coffie R.O., Burton M.P., Gibson F., Hailu A. (2016), Choice of rice production practices. A comparison between preference space and willingness to pay space, „Journal of Agricultural Economics", vol. 67 no. 3, pp. 799-819.

Donkoh S., Ayambila S., Abdulai S. (2013), Technical efficiency of rice production at the Tono Irrigation scheme in northern Ghana, „American Journal of Experimental Agriculture”, vol. 3 no. 1, pp. $25-42$.

Eling M., Luhnen M. (2008), Frontier efficiency methodologies to measure performance in the insurance industry. Overview and new empirical evidence, University of St. Gallen Working Papers on Risk Management and Insurance Paper, no. 56.

Emrouznejad A., Parker B.R., Tavares G. (2008), Evaluation of research in efficiency and productivity. A survey and analysis of the first 30 years of scholarly literature in DEA, „Socio-Economic Planning Sciences", vol. 42, pp. 151-157.

Farrell M.J. (1957), The measurement of productive efficiency, „Journal of the Royal Statistical Society. Series A (General)", vol. 120 no. 3, pp. 253-290.

Ferrier G.D., Hirschberg J.G. (1997), Bootstrapping confidence intervals for linear programming efficiency scores. With an illustration using Italian banking data, ,Journal of Productivity Analysis”, vol. 8 no. 1, pp. 19-33.

Fiorentino E., Karmann A., Koetter M. (2006), The cost efficiency of German banks. A comparison of SFA and DEA, „Deutsche Bundesbank Discussion Paper. Series 2: Banking and Financial Studies”, no. 10, http://citeseerx.ist.psu.edu/viewdoc/download?doi=10.1.1.137.4435\&rep=rep1\&type=pdf [09.09.2018].

Henningsen A., Henning C.H.C.A. (2009), Imposing regional monotonicity on translog stochastic production frontiers with a simple three-step procedure, „Journal of Productivity Analysis”, vol. 32, pp. 217-229.

JIRCAS (2012), Manual for improving rice production in Africa, https://www.jircas.go.jp/en/publication/research_results/2011_04 [09.09.2018].

Kumar S., Arora N. (2010), Analyzing regional variations in capacity utilization of Indian sugar industry using non-parametric frontier technique, „Eurasian Journal of Business \& Economics”, vol. 2 no. 4 , pp. 1-26. 


\section{BENCHMARKING TECHNICAL EFFICIENCY OF RICE FARMS IN GHANA...}

Kumbhakar S.C. (2003), Stochastic frontier analysis, Cambridge University Press, Cambridge.

Latruffe L., Balcombe K., Davidova S., Zawalinska K. (2004), Determinants of technical efficiency of crop and livestock farms in Poland, „Applied Economics”, vol. 36 no. 12, pp. 1255-1263.

Lothgren M. (1999), Bootstrapping the Malmquist productivity index. A simulation study, „Applied Economics", vol. 6 no. 11, pp. 707-710.

MOFA (2009), National rice development strategy, https://www.jica.go.jp/english/our_work/thematic_issues/agricultural/pdf/ghana_en.pdf [09.09.2018].

O’Donnell C.J., Coelli T.J. (2005), A Bayesian approach to imposing curvature on distance functions, „Journal of Econometrics”, vol. 126 no. 2, pp. 493-523.

Ofori-Bah A., Asafu-Adjaye J. (2011), Scope economies and technical efficiency of cocoa agroforestry systems in Ghana, „Ecological Economics”, vol. 70 no. 8, pp. 1508-1518.

Ragasa C., Dankyi A., Acheampong P., Wiredu A.N., Chapoto A., Asamoah M., Tripp R. (2013), Patterns of adoption of improved rice technologies in Ghana, International Food Policy Research Institute Working Paper no. 35, http://www.ifpri.org/publication/patterns-adoption-improved-ricetechnologies-ghana [09.09.2018].

Ravn K. (2014), Agriculture. The next frontier, „Nature”, no. 514, pp. S64-S65.

Richmond J. (1974), Estimating the efficiency of production, „International Economic Review”, vol. 15 no. 2 , pp. 515-521.

Seiford L.M. (1994), A DEA bibliography (1978-1992), in: Data Envelopment Analysis. Theory, Methodology, And Applications, Charnes A., Cooper W.W., Lewin A.Y., Seiford L.M. (ed.), Springer, Dordrecht.

Simar L., Wilson P.W. (1998), Sensitivity analysis of efficiency scores. How to bootstrap in nonparametric frontier models, „Management Science”, vol. 44 no. 1, pp. 49-61.

Simar L., Wilson P.W. (2007), Estimation and inference in two-stage, semi-parametric models of production processes, „Journal of Econometrics”, vol. 136 no. 1, pp. 31-64.

Theodoridis A., Psychoudakis A. (2008), Efficiency measurement in Greek dairy farms. Stochastic frontier vs. data envelopment analysis, „International Journal of Economic Sciences and Applied Research", vol. 1 no. 2, pp. 53-66.

Thiam, A., Bravo-Ureta, B. E. and Rivas, T. E. 2001. Technical efficiency in developing country agriculture: a meta-analysis. „Agricultural Economics, 25, 235-243.

Van Den Broeck, J., Koop, G., Osiewalski, J. and Steel, M. F. 1994. Stochastic frontier models: A Bayesian perspective. ,Journal of Econometrics, 61, 273-303. 